\title{
Electrical and optical properties of p-type InGaN
}

\author{
B. N. Pantha, A. Sedhain, J. Li, J. Y. Lin, and H. X. Jiang ${ }^{\text {a) }}$ \\ Department of Electrical and Computer Engineering, Texas Tech University, Lubbock, Texas 79409, USA
}

(Received 14 November 2009; accepted 4 December 2009; published online 29 December 2009)

\begin{abstract}
Mg-doped $\operatorname{In}_{x} \mathrm{Ga}_{1-x} \mathrm{~N}$ alloys were grown by metal organic chemical vapor deposition on semi-insulating c-GaN/sapphire templates. Hall effect measurements showed that $\mathrm{Mg}$-doped $\mathrm{In}_{x} \mathrm{Ga}_{1-x} \mathrm{~N}$ epilayers are p-type for $x$ up to 0.35 . Mg-acceptor levels $\left(E_{\mathrm{A}}\right)$ as a function of $x,(x$ up to 0.35 ), were experimentally evaluated from the temperature dependent hole concentration. The observed $E_{\mathrm{A}}$ in Mg-doped $\mathrm{In}_{0.35} \mathrm{Ga}_{0.65} \mathrm{~N}$ alloys was about $43 \mathrm{meV}$, which is roughly four times smaller than that in $\mathrm{Mg}$ doped $\mathrm{GaN}$. A room temperature resistivity as low as $0.4 \Omega \mathrm{cm}$ (with a hole concentration $\sim 5 \times 10^{18} \mathrm{~cm}^{-3}$ and hole mobility $\sim 3 \mathrm{~cm}^{2} / \mathrm{V} \mathrm{s}$ ) was obtained in Mg-doped $\mathrm{In}_{0.22} \mathrm{Ga}_{0.78} \mathrm{~N}$. It was observed that the photoluminescence (PL) intensity associated with the $\mathrm{Mg}$ related emission line decreases exponentially with $x$. The Mg energy levels in InGaN alloys obtained from PL measurements are consistent with those obtained from Hall-effect measurements. (C) 2009 American Institute of Physics. [doi:10.1063/1.3279149]
\end{abstract}

Achieving highly conductive p-type GaN and AlGaN is very difficult due to the high activation energies $\left(E_{\mathrm{A}}\right)$ of the $\mathrm{Mg}$-acceptor, which is a universally accepted p-type dopant for $\mathrm{GaN}$ and related alloys. ${ }^{1-3}$ Since $E_{\mathrm{A}}$ decreases with a decrease in band gap energy, ${ }^{3} \mathrm{Mg}$-doped $\mathrm{InGaN}$ (InGaN:Mg) is expected to have a higher hole concentration $(p)$ than $\mathrm{Mg}$ doped GaN. Additionally, p-type InGaN is synthesized at a much lower temperature compared to p-type GaN. Thus, the use of p-type InGaN instead of p-type $\mathrm{GaN}$ in device structures is beneficial, particularly in devices such as green laser diodes, long wavelength emitters, and solar cells, where the active region has to be grown at temperatures much lower than that of the top p-type GaN layer. Low etching damage and low contact resistance are other superior characteristics of p-type InGaN over p-type GaN. ${ }^{1}$ Improvements in the performance of $\mathrm{GaN}$ based devices using p-type InGaN either as a contact layer or as the p-layer itself has already been demonstrated. ${ }^{4-6}$ In recent years, applications of InGaN alloys have expanded into areas such as optoelectronics/ photonics, solar cells, photoelectrochemical cells for hydrogen generation, and thermoelectric materials for converting heat to electricity. ${ }^{7-12}$ For all these applications, high optical and electrical quality p-type $\mathrm{InGaN}$ is highly sought after. For hydrogen generation, p-type InGaN alloys are expected to be more stable in aqueous solutions than $\mathrm{n}$-type materials.

P-type doping in relatively high In content InGaN alloys is highly challenging due to the presence of high background electron concentrations, which is believed to originate from defects such as oxygen and hydrogen impurities or nitrogen vacancies. ${ }^{13,14}$ Nitrogen vacancies could be the consequence of an insufficiency of nitrogen atoms which results from the low decomposition rate of ammonia, as high In-content In$\mathrm{GaN}$ has to be grown at temperatures lower than $<800{ }^{\circ} \mathrm{C}$ (while the growth temperature of $\mathrm{GaN}$ is generally $>1000{ }^{\circ} \mathrm{C}$ ). Although the synthesis of p-type InGaN has been reported as early as in $1995,{ }^{15}$ there are only a few reports on the properties of p-type InGaN. ${ }^{1,16-20}$ However, the use of high In-content p-InGaN is inevitable in the near future as nitride based devices are rapidly expanding toward

\footnotetext{
${ }^{a)}$ Electronic mail: hx.jiang@ttu.edu.
}

longer wavelength emitters. ${ }^{7}$ We report on the synthesis and systematic studies on the electrical and optical properties of $\mathrm{Mg}$ doped p-type $\operatorname{In}_{x} \mathrm{Ga}_{1-x} \mathrm{~N}$ alloys, for $x$ up to 0.35 .

Mg-doped p-type $\operatorname{In}_{x} \mathrm{Ga}_{1-x} \mathrm{~N}$ alloys $(0 \leq x \leq 0.35)$ were grown on semi-insulating c-GaN (SI-GaN)/sapphire templates by metal organic chemical vapor deposition (MOCVD). We have chosen SI-GaN templates to minimize electrical measurement errors of top InGaN:Mg alloys. Since the p-type $\operatorname{In}_{x} \mathrm{Ga}_{1-x} \mathrm{~N}$ layer is relatively thin $(\sim 200 \mathrm{~nm})$, resistivity of the layer underneath has to be high in order to assure accuracy of the measurement results. Ammonia $\left(\mathrm{NH}_{3}\right)$, trimethylgallium (TMGa), trimethylindium (TMIn), and biscyclopentadienyl-magnesium $\left(\mathrm{Cp}_{2} \mathrm{Mg}\right)$, were used as $\mathrm{N}, \mathrm{Ga}, \mathrm{In}$, and $\mathrm{Mg}$ sources. $\mathrm{N}_{2}$ gas was used as a carrier gas. Growth temperatures were varied from 1050 to $740{ }^{\circ} \mathrm{C}$ to increase $x$ from 0 to 0.35 . A variable temperature Hall-effect experiment was performed to measure the hole concentration $(p)$, hole mobility $\left(\mu_{\mathrm{h}}\right)$, and resistivity $(\rho)$ of the samples. Photoluminescence (PL) spectra were measured using a Tisapphire laser spectroscopy system coupled with a tripler. This system gives an average output power of about $40 \mathrm{~mW}$ at $4.7 \mathrm{eV}$ and a spectral resolution of about $0.2 \mathrm{meV}^{21} \mathrm{In}$ dium contents were determined from the peak angles of (002) $\omega$-2 $\theta$ x-ray diffraction (XRD) curves and using Vegard law.

The room temperature electrical properties of p-type $\mathrm{In}_{x} \mathrm{Ga}_{1-x} \mathrm{~N}: \mathrm{Mg}$ alloys as functions of $x$ are plotted in Fig. 1. It was found that $p$ continuously increases from $2 \times 10^{17}$ for $x=0(\mathrm{GaN})$ to $5 \times 10^{18} \mathrm{~cm}^{-3}$ when $x=0.22$. $\mu_{\mathrm{h}}$ was found to decrease from 15 to $1.8 \mathrm{~cm}^{2} / \mathrm{V} \mathrm{s}$ as $x$ increases from 0 to 0.35 . The variation in $\rho$ with $x$ shows that $\rho$ decreases as $x$ increases and reaches a minimum value of $0.4 \Omega \mathrm{cm}$ at $x$ $=0.22\left(\operatorname{In}_{0.22} \mathrm{Ga}_{0.78} \mathrm{~N}\right)$. This value of $\rho$ is among the lowest reported for $\mathrm{p}$-type InGaN. Though an even higher $\rho$ value has been reported for similar In-content InGaN: $\mathrm{Mg}^{18}$ and GaN:Mg grown by molecular beam epitaxy, ${ }^{22} \mu_{\mathrm{h}}$ values of our samples are higher, which results in lower values of $\rho$. Higher $\mu_{\mathrm{h}}$ values are a result of enhanced material quality, while reduced $\rho$ values will significantly improve device performance for many practical applications. The reduction in $p$ values observed in p-type $\operatorname{In}_{x} \mathrm{Ga}_{1-x} \mathrm{~N}$ with $x>0.22$ are due to 


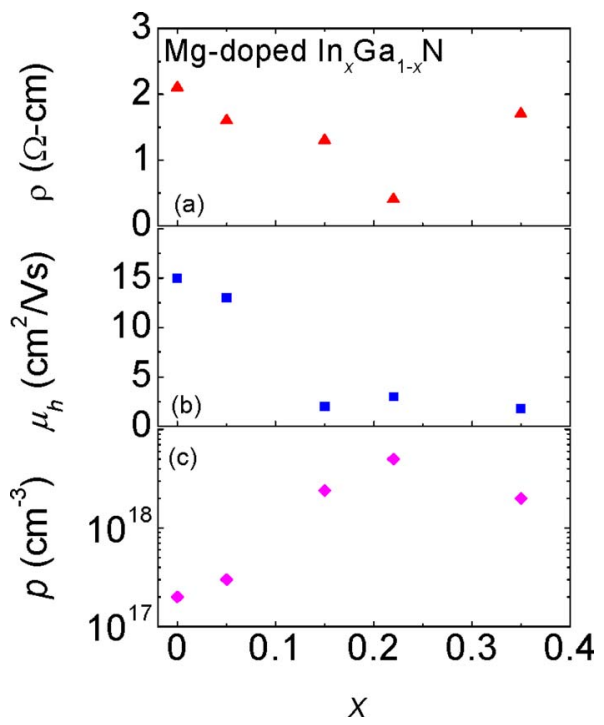

FIG. 1. (Color online) Room temperature (a) resistivity $\rho$, (b) hole mobility $\mu_{\mathrm{h}}$, and (c) hole concentration $p$ as functions of In content $(x)$ in Mg doped $\mathrm{In}_{x} \mathrm{Ga}_{1-x} \mathrm{~N}$ alloys.

the effect of hole compensation by background electrons. The presence of high background electron concentration is the main hindrance for obtaining p-type conductivity and p-type $\mathrm{In}_{x} \mathrm{Ga}_{1-x} \mathrm{~N}$ alloys with In content $x>0.35$.

Temperature dependent $p$ of p-type $\operatorname{In}_{x} \mathrm{Ga}_{1-x} \mathrm{~N}$ alloys was also measured. Figure 2 shows the Arrhenius plot of free hole concentration $p$ for $x=0.05,0.15,0.22$, and 0.35 . Straight lines are linear fits of the experimental data of $p$ by the following equation:

$$
p=p_{o} e^{-E_{\mathrm{A}} / k_{\mathrm{B}} T},
$$

where $E_{\mathrm{A}}$ is $\mathrm{Mg}$ energy level and $k_{\mathrm{B}}$ is the Boltzmann constant. The plot of $E_{\mathrm{A}}$ as a function of $x$ for $\operatorname{In}_{x} \mathrm{Ga}_{1-x} \mathrm{~N}: \mathrm{Mg}$ alloys is shown in Fig. 3 along with other reported values. ${ }^{1,17,19}$ It was found that $E_{\mathrm{A}}$ continuously decreases with an increase in $x$. Lower values of $E_{\mathrm{A}}$ are the main physical reason for higher values of $p$ in $\operatorname{In}_{x} \mathrm{Ga}_{1-x} \mathrm{~N}: \mathrm{Mg}$ alloys of higher $x$. An $E_{\mathrm{A}}$ value as low as $43 \mathrm{meV}$ was measured in $\mathrm{In}_{0.35} \mathrm{Ga}_{0.65} \mathrm{~N}: \mathrm{Mg}$. This value is approximately four times

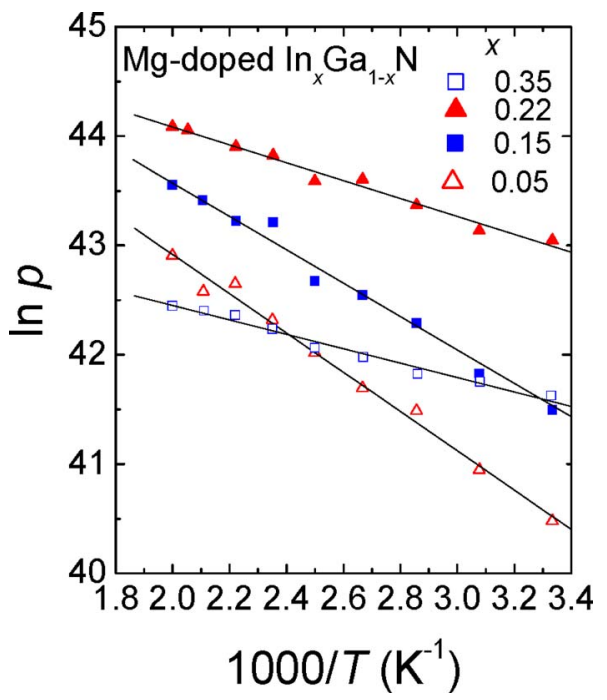

FIG. 2. (Color online) The Arrhenius plot of free hole concentration in $\mathrm{Mg}$ doped $\operatorname{In}_{x} \mathrm{Ga}_{1-x} \mathrm{~N}$ alloys.

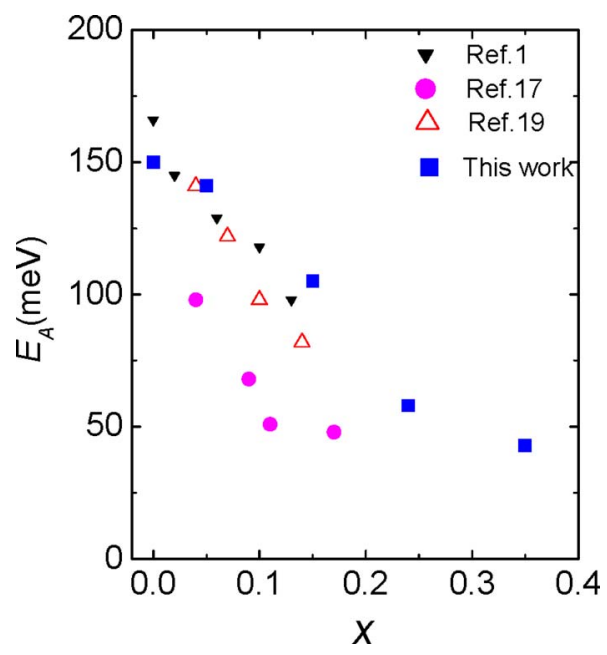

FIG. 3. (Color online) Energy level $\left(E_{\mathrm{A}}\right)$ of $\mathrm{Mg}$ acceptors in $\mathrm{Mg}$ doped $\mathrm{p}-\mathrm{In}_{x} \mathrm{Ga}_{1-x} \mathrm{~N}$ alloys as a function of In content $x$. Data from references available up to $x=0.17$ are also included.

smaller than that of Mg-doped GaN. $\operatorname{In}_{x} \mathrm{Ga}_{1-x} \mathrm{~N}$ materials with $x>0.35$ are generally highly $\mathrm{n}$-type and conversion of these materials to p-type by $\mathrm{Mg}$ doping is still very difficult. Our results indicate that p-type conductivity in $\mathrm{InGaN}: \mathrm{Mg}$ could be further improved if a better control of the background electron concentration could be achieved. The issues of high background electron concentration in InGaN alloys with relatively high In content is currently under intensive investigation $^{11,12}$ and a significant improvement in the p-type conductivity of relatively high In content alloys is anticipated.

Figure 4 shows low temperature $(10 \mathrm{~K})$ PL spectra of $\operatorname{In}_{x} \mathrm{Ga}_{1-x} \mathrm{~N}: \mathrm{Mg}$ for $x=0,0.05,0.11$, and 0.22 . We observed that the spectra for GaN:Mg is dominated by a broad emission band centered around $2.90 \mathrm{eV}$, which is a donoracceptor-pair type transition involving a deep donor, $\mathrm{D}^{\circ}$, and an $\mathrm{Mg}$-acceptor, $\mathrm{Mg}^{\mathrm{O}}$. Deep donors appeared in $\mathrm{Mg}$ doped $\mathrm{GaN}$ but disappeared in all $\mathrm{InGaN}: \mathrm{Mg}$ alloys. One speculation is that the lower growth temperatures employed for In$\mathrm{GaN}$ alloys somehow suppresses the formation of these deep donors. A relatively weak feature in the higher energy side

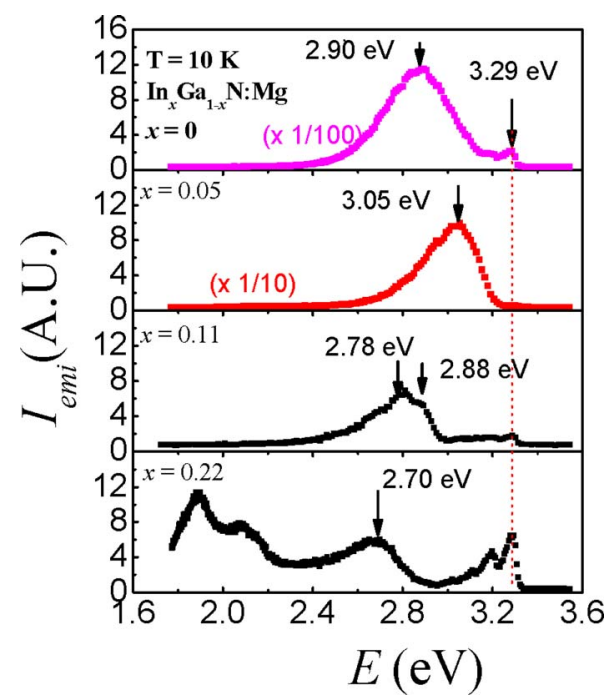

FIG. 4. (Color online) PL spectra of Mg-doped p-type $\operatorname{In}_{x} \mathrm{Ga}_{1-x} \mathrm{~N}$ alloys measured at temperature $10 \mathrm{~K}$. 


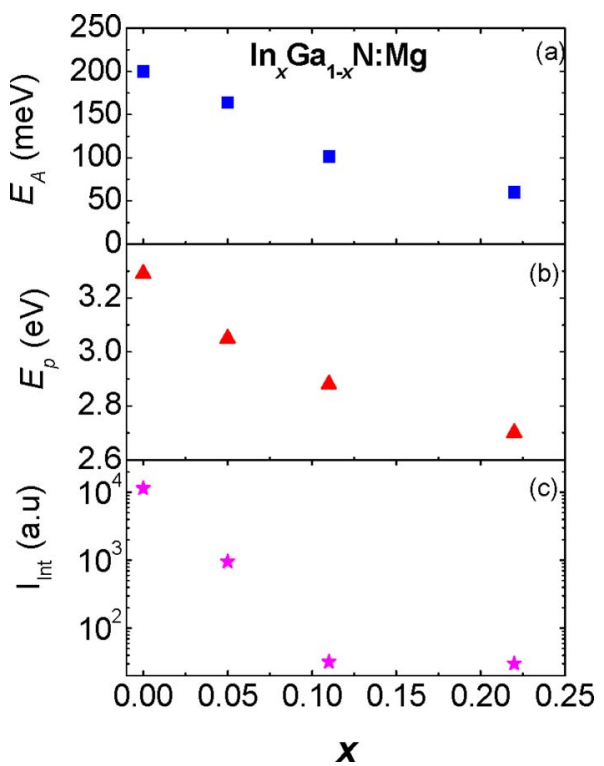

FIG. 5. (Color online) $\mathrm{Mg}$ acceptor energy levels $E_{A}$, peak position of $\mathrm{Mg}$ related emission $E_{\mathrm{p}}$, and integrated PL intensity $I_{\text {int }}$ as functions of In content $x$. (a) $E_{\mathrm{A}}$, (b) $E_{\mathrm{p}}$, and (c) $I_{\text {int }}$.

(with a peak at $3.29 \mathrm{eV}$ ) is a band-to-impurity type transition involving the conduction band $\left(\mathrm{e}^{-}\right)$and acceptor $\left(\mathrm{Mg}^{\mathrm{O}}\right)$ which is believed to dominate the spectra of $\mathrm{GaN}$ with light or moderate $\mathrm{Mg}$ doping. All p-type $\operatorname{In}_{x} \mathrm{Ga}_{1-x} \mathrm{~N}: \mathrm{Mg}$ spectra except the GaN:Mg sample show the dominant peak with the same mechanism as that of the $3.29 \mathrm{eV}$ line in GaN:Mg $\square$ namely, a band-to-impurity transition involving the conduction band $\left(\mathrm{e}^{-}\right)$and acceptor $\left(\mathrm{Mg}^{\circ}\right)$. An emission line at 3.29 $\mathrm{eV}$ also appeared in the spectra for samples with $x=0.11$ and 0.22 . This emission line is related to the SI-GaN template, which was lightly doped with $\mathrm{Mg}$ to achieve semi-insulation. From the PL peak positions observed here and the band-gap values already reported in the literature, ${ }^{11}$ we have estimated the acceptor level of $\mathrm{Mg}$ in our $\operatorname{In}_{x} \mathrm{Ga}_{1-x} \mathrm{~N}$ epilayers, which is plotted in Fig. 5. As expected, $\mathrm{Mg}$ levels in $\operatorname{In}_{x} \mathrm{Ga}_{1-x} \mathrm{~N}$ alloys decrease with In-content and are consistent with those obtained from the electrical measurement results shown in Fig. 3. The Mg impurity related PL emission intensity is found to decrease exponentially with In-content, as shown in Fig. 5. The PL emission intensity of $\mathrm{Mg}$ doped $\mathrm{In}_{0.22} \mathrm{Ga}_{0.78} \mathrm{~N}$ is almost three orders of magnitude lower than that of $\mathrm{Mg}$ doped GaN. The reduction in PL intensity may be related with the incorporation of impurities, which are also responsible for the high background electron concentrations in high In content InGaN alloys.

In summary, we have synthesized Mg-doped p-type $\mathrm{In}_{x} \mathrm{Ga}_{1-x} \mathrm{~N}$ alloys by MOCVD for $x$ up to 0.35 and analyzed their electrical and optical properties. P-type resistivity in $\mathrm{Mg}$-doped InGaN alloys was found to be lower than that of Mg-doped GaN. Resistivity as low as $0.4 \Omega \mathrm{cm}$ with a free hole concentration as high as $5 \times 10^{18} \mathrm{~cm}^{-3}$ was measured in
$\mathrm{Mg}$ doped $\mathrm{In}_{0.22} \mathrm{Ga}_{0.78} \mathrm{~N}$. We have measured the $\mathrm{Mg}$ acceptor energy levels $\left(E_{\mathrm{A}}\right)$ in p- $\mathrm{In}_{x} \mathrm{Ga}_{1-x} \mathrm{~N}$ alloys for $x$ up to $0.35 . E_{\mathrm{A}}$ as low as $43 \mathrm{meV}$ was obtained in $\mathrm{Mg}$ doped $\mathrm{In}_{0.35} \mathrm{Ga}_{0.65} \mathrm{~N}$. From low temperature PL measurements, we found $\mathrm{Mg}$ acceptor levels for $x$ up to 0.22 and the results are in close agreement with those obtained from electrical measurements. The difficulties of obtaining p-type InGaN in relatively high In-content are due to the high background election concentrations caused by the lower growth temperature of InGaN alloys, which seems to promote the incorporation of donor like defects and impurities.

InGaN growth and optical characterization work is supported by NSF (Grant No. DMR0906879). The effort of achieving p-type conduction in $\mathrm{InGaN}_{\text {is }}$ supported by DARPA and monitored by Dr. Michael Haney and Dr. John Zavada. H.X.J. and J.Y.L. would like to acknowledge the support of Edward Whitacre and Linda Whitacre endowed chairs through the AT\&T foundation.

${ }^{1}$ K. Kumakura, T. Makimoto, and N. Kobayashi, J. Appl. Phys. 93, 3370 (2003).

${ }^{2}$ W. Götz, N. M. Johnson, J. Walker, D. P. Bour, and R. A. Street, Appl. Phys. Lett. 68, 667 (1996).

${ }^{3}$ J. Li, T. N. Oder, M. L. Nakarmi, J. Y. Lin, and H. X. Jiang, Appl. Phys. Lett. 80, 1210 (2002)

${ }^{4}$ T. Makimoto, K. Kumakura, and N. Kobayashi, Appl. Phys. Lett. 79, 380 (2001).

${ }^{5}$ K. Kumakura, T. Makimoto, and N. Kobayashi, Appl. Phys. Lett. 79, 2588 (2001).

${ }^{6}$ P. C. Chen, C. H. Chen, S. J. Chang, Y. K. Su, P. C. Chang, and B. R. Huang, Thin Solid Films 498, 113 (2006).

${ }^{7}$ J. Wu, J. Appl. Phys. 106, 011101 (2009).

${ }^{8}$ R. Dahal, B. Pantha, J. Li, J. Y. Lin, and H. X. Jiang, Appl. Phys. Lett. 94, 063505 (2009).

${ }^{9}$ K. Fujii and K. Ohkawa, Jpn. J. Appl. Phys. 44, L909 (2005).

${ }^{10}$ J. Li, J. Y. Lin, and H. X. Jiang, Appl. Phys. Lett. 93, 162107 (2008).

${ }^{11}$ B. N. Pantha, R. Dahal, J. Li, J. Y. Lin, H. X. Jiang, and G. Pomrenke, Appl. Phys. Lett. 92, 042112 (2008); J. Electron. Materials 38, 1132 (2009).

${ }^{12}$ N. Kobayashi, T. Narumi, and R. Morita, Jpn. J. Appl. Phys., Part 2 44, L784 (2005)

${ }^{13}$ C. G. Van de Walle and D. Segev, J. Appl. Phys. 101, 081704 (2007).

${ }^{14}$ J. W. L. Yim, R. E. Jones, K. M. Yu, J. W. Ager III, W. Walukiewicz, W. J. Schaff, and J. Wu, Phys. Rev. B 76, 041303(R) (2007).

${ }^{15}$ S. Yamasaki, S. Asami, N. Shibata, M. Koike, K. Manabe, T. Tanaka, H. Amano, and I. Akasaki, Appl. Phys. Lett. 66, 1112 (1995).

${ }^{16}$ K. Kumakura, T. Makimoto, and N. Kobayashi, Jpn. J. Appl. Phys., Part 2 39, L337 (2000).

${ }^{17}$ K. Kumakura, T. Makimoto, and N. Kobayashi, J. Cryst. Growth 221, 267 (2000).

${ }^{18}$ T. C. Wen, W. I. Lee, J. K. Sheu, and G. C. Chi, Solid-State Electron. 45, 427 (2001).

${ }^{19}$ D. Iida, M. Iwaya, S. Kamiyama, H. Amano, and I. Akasaki, Appl. Phys. Lett. 93, 182108 (2008).

${ }^{20}$ C. A. Chang, T. Y. Tang, P. H. Chang, N. C. Chen, and C. T. Liang, Jpn. J. Appl. Phys., Part 1 46, 2840 (2007).

${ }^{21}$ Research page, nanophotonics research at TTU (http://www2.ece.ttu.edu/ nanophotonics/).

${ }^{22}$ G. Namkoong, E. Trybus, K. K. Lee, M. Moseley, W. A. Doolittle, and D. C. Look, Appl. Phys. Lett. 93, 172112 (2008). 